\title{
Photodegradation of Brilliant Green Dye by a Zinc bioMOF and Crystallographic Visualization of Resulting $\mathrm{CO}_{2}$
}

\author{
Paula Escamilla ${ }^{1}{ }^{(}$, Marta Viciano-Chumillas ${ }^{1}$, Rosaria Bruno ${ }^{2}\left(\mathbb{D}\right.$, Donatella Armentano ${ }^{2, *} \mathbb{C}$, Emilio Pardo ${ }^{1, *(\mathbb{C})}$ \\ and Jesús Ferrando-Soria $1, *$ (D) \\ 1 Departament de Química Inorgànica, Instituto de Ciencia Molecular (ICMOL), Universitat de València, \\ Paterna, 46980 València, Spain; paula.escamilla@uv.es (P.E.); marta.viciano@uv.es (M.V.-C.) \\ 2 Dipartimento di Chimica e Tecnologie Chimiche, Università della Calabria, 87036 Cosenza, Italy; \\ rosaria.bruno@unical.it \\ * Correspondence: Donatella.armentano@unical.it (D.A.); emilio.pardo@uv.es (E.P.); \\ jesus.ferrando@uv.es (J.F.-S.)
}

check for

updates

Citation: Escamilla, P.; Viciano-

Chumillas, M.; Bruno, R.; Armentano,

D.; Pardo, E.; Ferrando-Soria, J.

Photodegradation of Brilliant Green

Dye by a Zinc bioMOF and

Crystallographic Visualization of

Resulting $\mathrm{CO}_{2}$. Molecules 2021, 26,

4098. https://doi.org/10.3390/

molecules 26134098

Academic Editor: Liudmil Antonov

Received: 10 June 2021

Accepted: 2 July 2021

Published: 5 July 2021

Publisher's Note: MDPI stays neutral with regard to jurisdictional claims in published maps and institutional affiliations.

Copyright: (C) 2021 by the authors. Licensee MDPI, Basel, Switzerland. This article is an open access article distributed under the terms and conditions of the Creative Commons Attribution (CC BY) license (https:// creativecommons.org/licenses/by/ $4.0 /)$.

\begin{abstract}
We present a novel bio-friendly water-stable Zn-based MOF (1), derived from the natural amino acid $L$-serine, which was able to efficiently photodegrade water solutions of brilliant green dye in only $120 \mathrm{~min}$. The total degradation was followed by UV-Vis spectroscopy and further confirmed by single-crystal X-ray crystallography, revealing the presence of $\mathrm{CO}_{2}$ within its channels. Reusability studies further demonstrate the structural and performance robustness of $\mathbf{1}$.
\end{abstract}

Keywords: metal-organic frameworks; amino acids-derived ligands; water remediation; photocatalytic degradation; single-crystal X-ray crystallography

\section{Introduction}

One of the main challenges that modern society faces is related, undoubtedly, to the contamination of aquatic environments, which is mainly caused by human/industrial activities [1,2]. Among the wide diversity of inorganic/organic chemical pollutants, organic dyes - waste generated in the cosmetic, textile, tannery, or food industries, among othersconstitute one of the major contaminants in industrial wastewater [3].

Proposed solutions for the removal of such organic contaminants include precipitation, coagulation/flocculation, membrane technology, or biological processes [4]. However, probably the two most promising technologies for this purpose are based on the straightforward capture of the organic dyes by a porous material or their in-situ photocatalytic degradation $[5,6]$. In particular, metal-organic frameworks (MOFs) are porous crystalline materials that have already been shown to be efficient in the last two approaches [7-13].

MOFs [14,15] attract broad attention from many research groups given the great variety of applications they can exhibit [14-21]. The reasons for such a variety of applications are related to a number of unique characteristics such as permanent porosity [22,23], a thrilling host-guest chemistry $[24,25]$ — which can be tuned for fine control over the size, shape, and functionality of MOF channels-and the possibility of using single-crystal X-ray diffraction [26-31] (SCXRD) to visualize what is going on within their channels [32].

In particular, MOFs have recently been used in water remediation with exceptional results. For example, the easy of functionalizing, pre- or post-synthetically, MOF channels has led to the preparation of specifically designed MOFs for the selective and efficient capture of both organic and inorganic contaminants [8,33-35]. Moreover, certain specifically designed MOFs have already been shown to be effective as photocatalysts to degrade organic pollutants-i.e., organic dyes-into less toxic intermediates or fully degrade them into $\mathrm{CO}_{2}$ and $\mathrm{H}_{2} \mathrm{O}$ [10,36-40]. In particular, several $\mathrm{Zn}$ (II)-based MOFs have recently been reported, showing, by analogy with zinc oxide based photocatalysts [41,42], moderately good efficiencies as photocatalysts towards different organic dyes [43-45]. 


\section{Results}

In this communication, we report the preparation and total characterization of a novel eco-friendly $\mathrm{Zn}$-based MOF, derived from the natural amino acid $L$-serine, with formula $\left\{\mathrm{Zn}^{\mathrm{II}}{ }_{2}[(S, S)\right.$-serimox $\left.]\left(\mathrm{H}_{2} \mathrm{O}\right)_{2}\right] \cdots \mathrm{H}_{2} \mathrm{O}(\mathbf{1})((S, S)$-serimox = [bis[(S)-serine $]$ oxalyl diamide $]$ (Figure 1a,b). The final material is capable of photodegrading brilliant green (BG) dye (Figure 1c) in only 120 min with an efficiency of 100\% in the absence of any other oxidant or co-catalyst. In addition, the high robustness and crystallinity of 1 also allowed us to obtain the crystal structure of 1-with the help of SCXRD—after the photocatalytic process, which shows, unambiguously, the presence, within the channels, of $\mathrm{CO}_{2}$ molecules resulting from the photodegradation of BG dyes.

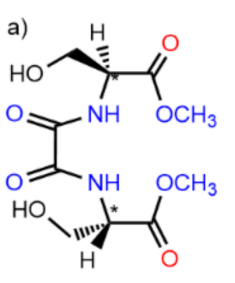<smiles>CCN(CC)c1ccc(C(=C2C=CC(=[N+](CC)CC)C=C2)c2ccccc2)cc1</smiles>

Figure 1. Chemical formulas of the proligand $(S, S)$-serimox (a) and the secondary building units (SBU) consisting of $\mathrm{Zn}^{\mathrm{II}}$ dinuclear units (b). Red oxygen atoms coordinate $\mathrm{Zn}^{\mathrm{II}}$ atoms from another SBU, whereas green oxygen atoms belong to neighboring SBUs. (c) Chemical formula of brilliant green dye.

The crystal structure of 1 was first determined at $100 \mathrm{~K}$. It crystallizes in the chiral $P 4_{1}{ }_{1} 2$ space group of the tetragonal system and consists of a chiral 3D pillared square grid where $\left[\mathrm{Zn}_{2}{ }_{2}(S, S)\right.$-serimox] moieties are located on the vertices of the edges (Figures 2 and 3a). The robust uni-nodal three-connected srs nets are built up from trans oxamidato-bridged $\mathrm{Zn}$ (II) dimeric units, $\left\{\mathrm{Zn}^{\mathrm{II}}{ }_{2}[(\mathrm{~S}, \mathrm{~S})\right.$-serimox $\left.]\right\}$ (Figure 2 and Figure S1), which are connected to each other through their carboxylate groups (Figure 2, Figures S1 and S2).
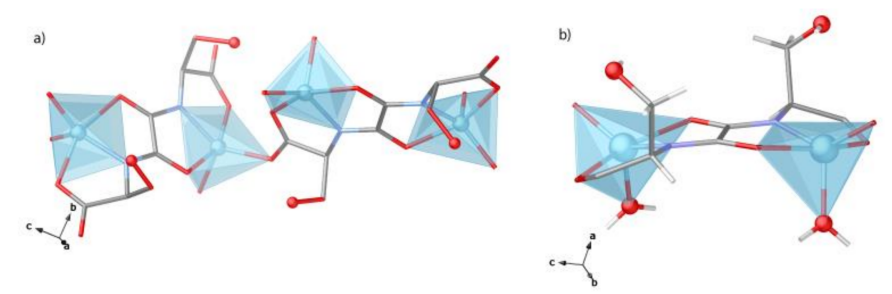

Figure 2. Perspective view of a fragment of 1 emphasizing the central dinuclear $\mathrm{Zn}_{2}$ SBU (b) unit and their connection to neighboring $\mathrm{Zn}^{2+}$ cations (a). Color code: $\mathrm{Zn}, \mathrm{O}$, and $\mathrm{N}$ atoms are represented as cyan, red, and deep blue spheres, respectively, whereas $\mathrm{C}$ atoms are depicted as grey sticks.

Within the $\left\{\mathrm{Zn}_{2}{ }_{2}[(\mathrm{~S}, \mathrm{~S})\right.$-serimox $\left.]\right\}$ moieties, each $\mathrm{Zn}(\mathrm{II})$ metal ion results in a highly distorted pyramidal coordination being linked by nitrogen and oxygen atoms from the serimox ligand [Zn-N 1.985(4) $\AA$ and $\mathrm{Zn}-\mathrm{O}_{\text {ser }}$ ranging from 1.958(3) to 2.215(4) $\AA$ ] and a terminal water molecule [ $\left.\mathrm{Zn}-\mathrm{O}_{\text {water }} 2.011(4) \AA\right]$ (Figure 2b). The 3D network features two types of small pore, different in size and shape, propagating along the $b$ and $c$ axes (Figure 3, Figures S2 and S3). Hydrophilic square sized pores (Figure 3a, left and Figure S3) and hydrophilic irregular pores of medium size (virtual diameters of ca. 0.30 and $0.40 \mathrm{~nm}$, respectively) (Figure 3a, right and Figure S2) are decorated by the primary alcohol group of serine moieties, pointing inwards towards the voids, and accountable for its resulting host-guest chemistry. 


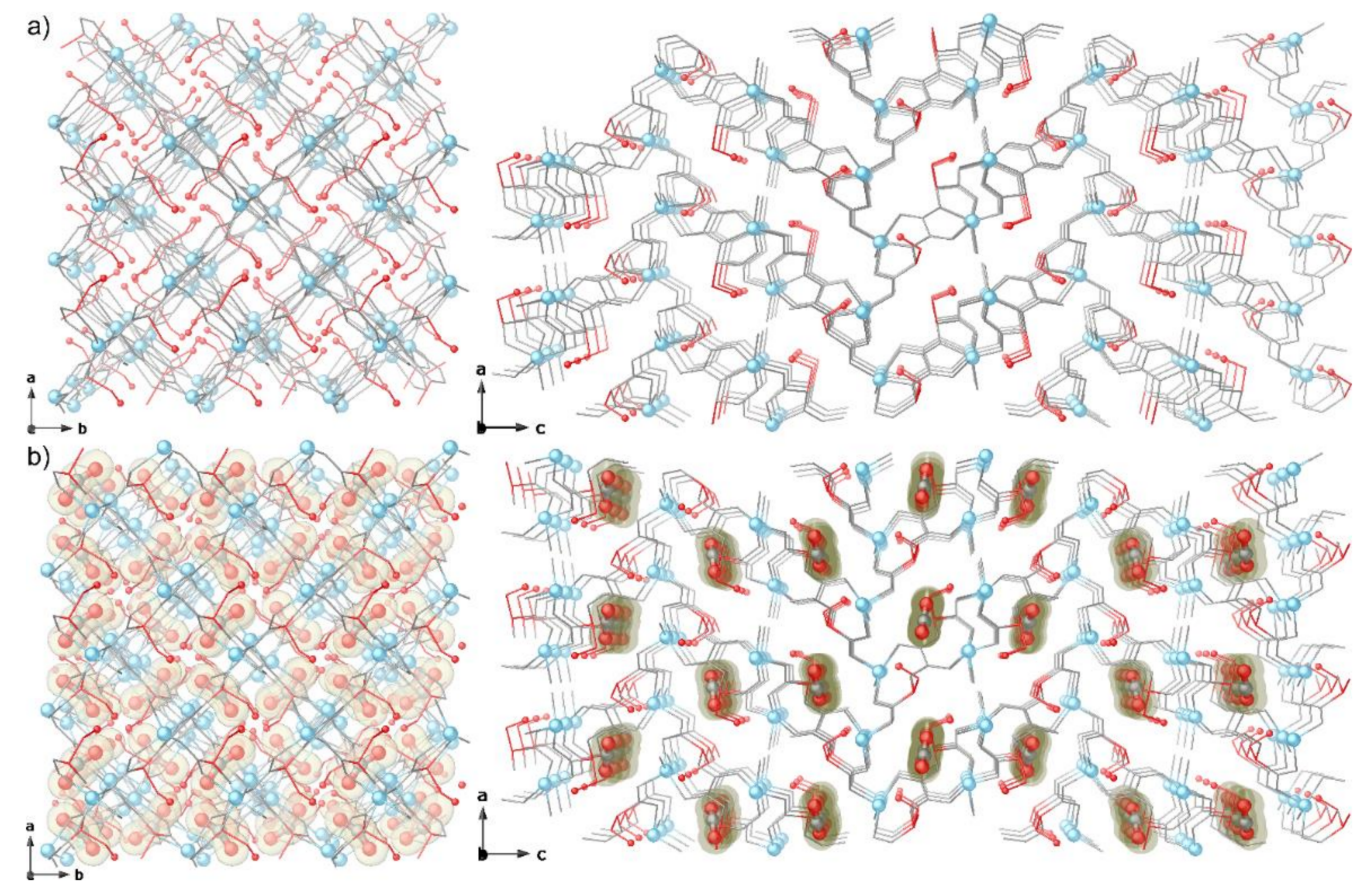

Figure 3. Perspective views of the porous networks of 1 (a) and $\mathrm{CO}_{2} @ 1(\mathbf{b})$ along the $c(\mathbf{l e f t})$ and $b$ (right) axes. Color code: $\mathrm{Zn}$ atoms and $\mathrm{C}$ and $\mathrm{O}$ from guest $\mathrm{CO}_{2}$ molecules are represented as cyan, grey, and red spheres, whereas serimox ligands-with the exception of serine residues-are represented by grey sticks. $-\mathrm{CH}_{2} \mathrm{OH}$ groups and $\mathrm{N}$ atoms are represented as cyan, red, and deep blue spheres, respectively, whereas $\mathrm{C}$ atoms are depicted as grey sticks.

Crystals of 1, left in a sealed glass tube containing an aqueous solution of BG dye for one week, after irradiation in the range $250-350 \mathrm{~nm}$ for $60 \mathrm{~min}$ were analyzed by SCXRD at a temperature of $100 \mathrm{~K}$ and the crystal structure of $\mathrm{CO}_{2} @ 1$ was determined, revealing a slight deformation of the framework-likely correlated to $\mathrm{CO}_{2}$ adsorption process-but still isomorphous to 1 , crystallizing in the $P_{1} 2_{1} 2$ space group. Adsorption of $\mathrm{CO}_{2}$ gasproduced by the photocatalytic process at $298 \mathrm{~K}$-results in linear negative expansion. Pores that run parallel to the $c$-axis contract upon $\mathrm{CO}_{2}$ inclusion $(\Delta \mathrm{a}, \Delta \mathrm{b}$ slightly $<0 ; \Delta \mathrm{c}<0$; $\Delta \mathrm{V}<0)$. The largest change in dimensions is observed for the $c$ axis, accounting for a small decrease in the unit-cell volume $\left(\Delta \mathrm{V} \approx 48 \AA^{3}\right.$, Table S1).

The crystal structure of the adsorbate $\mathrm{CO}_{2} @ 1$ clearly evidences the presence of $\mathrm{CO}_{2}$ guest molecules hosted in the hydrophilic irregular pores of 1 (Figure 3b, Figures S4 and S6. A primary adsorption site can be identified on the $\mathrm{CO}_{2}$ molecule (Figure 4), where the plane containing the ligands are situated at only 2.83(1) $\AA$ [distance between centroid of oxamate core and $\mathrm{C}$ atom of $\mathrm{CO}_{2}$ molecule] from the $\mathrm{C}$ atom of $\mathrm{CO}_{2}$ molecules occupying the primary site, suggesting an interaction between the $\mathrm{C}\left(\delta^{+}\right)$atom of the $\mathrm{CO}_{2}$ molecule and the $\mathrm{O}$ lone pair of the oxamate core of the ligand, as observed before [46]. The described guest molecule orientation generates a kind of $\pi\left(\mathrm{CO}_{2}\right) \cdots \pi$ (oxamate) dimer exhibiting $\mathrm{C}$ (oxamate) $\cdots \mathrm{O}\left(\mathrm{CO}_{2}\right)$ and $\mathrm{C}\left(\mathrm{CO}_{2}\right) \cdots \mathrm{O}$ (oxamate) symmetric contacts of 3.08(1) and 3.32(1) $\AA$, respectively. The secondary adsorption sites identified are situated at the center of the pores, where $\mathrm{CO}_{2}$ molecules are packed with closest contact with the framework through the $\mathrm{H}_{2} \mathrm{C}$ - and $\mathrm{HC}$ - of the ligand [shortest O-C-O $\cdots \cdot \mathrm{H}-\mathrm{C}$ - at 2.04(3) and 2.09(3) $\AA$, for $\mathrm{H}_{2} \mathrm{C}$ and HC- fragments, respectively] (Figure 4, Figures S4 and S5). The alcoholic fragment makes a contribution as well, being situated very close to $\mathrm{CO}_{2}$ molecules [O-C-O $\cdots \mathrm{H}-\mathrm{O}-$ and $\mathrm{HO} \cdots \mathrm{O}-\mathrm{C}-\mathrm{O}$ at 2.11(6) and 2.63(3) $\AA$, respectively]. Despite the supposed flexibility and structural adaptability that serine residues could offer, no important differences in the alcoholic chain conformations have been observed in the $\mathrm{CO}_{2} @ 1$ adsorbate with respect to 1, where only $\mathrm{Zn}-\mathrm{O}_{\text {ser }}$ [ranging from 1.935(3) to 2.191(4) $\AA$ ] distances show a slight 
contraction with respect to 1, while $\mathrm{Zn}-\mathrm{O}_{\text {water }}[1.992(4) \AA]$, and Zn-N bond lengths [1.959(4) $\AA]$ fall in the range of the expected values for $\mathrm{Zn}(\mathrm{II})$ metal ions [47].

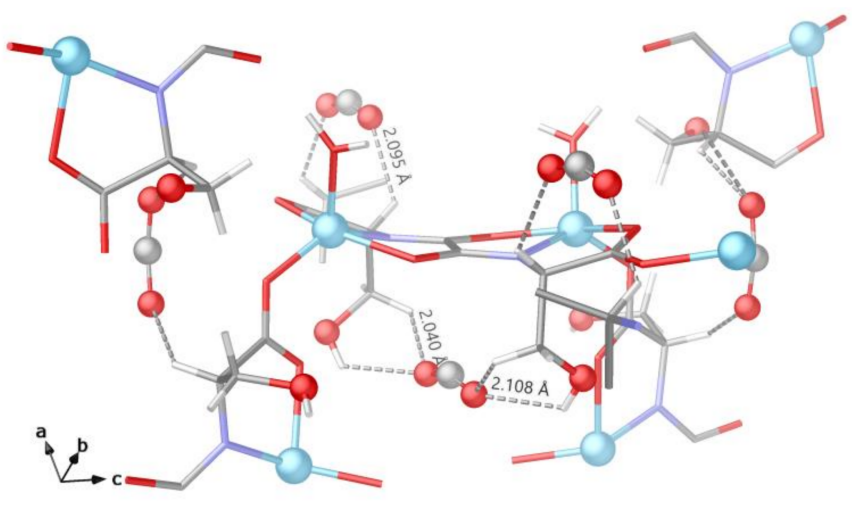

Figure 4. Details of $\mathrm{CO}_{2} @ 1$ crystal structure showing the adsorption sites identified for $\mathrm{CO}_{2}$ adsorbed molecules. Color code as in Figure 3.

What is worth underlining is the unusual penta-coordination of $\mathrm{Zn}(\mathrm{II})$ ions observed in 1 and $\mathrm{CO}_{2} @ 1$, reminiscent (in geometry) of that observed for the catalytic metal ions of the di-zinc aminopeptidase from Aeromonas proteolytica (AAP) [48]. Surveys of the Cambridge Structural Database (CSD) show zinc ion coordination number frequencies of ca. $60 \%$ and $25 \%$ for 4 and 6 coordination numbers, respectively. Interestingly, the zinc ion coordination prevalence in protein sites depends on whether the zinc plays a structural or a catalytic role. In structural zinc sites, the occurrence rate for 4, 5, and 6 coordination numbers is $80 \%, 6 \%$, and $12 \%$, respectively; whereas in catalytic zinc sites, the occurrence rate for 4,5 , and 6 coordination is $47 \%, 45 \%$, and $6 \%$, respectively [49]. Thus, five coordinate, or geometrically strained zinc sites, may represent sites equipped for catalysis, whereas four coordinate ideal tetrahedral zinc sites may represent stable sites affiliated with structural support.

Single-crystal X-ray experiment on samples of 1 after irradiation with UV light (without $\mathrm{BG}$ dye) do not show the presence of $\mathrm{CO}_{2}$ molecules, just coordinated water and small voids with light diffuse electron density. This ruled out the possibility of $\mathrm{CO}_{2}$ adsorption from air or solvent in 1 , and reinforced our hypothesis that $\mathrm{CO}_{2} @ 1$ comes from the decomposition of the BG dye.

The experimental powder X-ray diffraction (PXRD) pattern of a polycrystalline sample of 1 is shown in Figure 5. It is consistent with the theoretical one and confirms the purity and homogeneity of the bulk sample. The solvent contents were determined by thermogravimetric analysis (TGA) under a dry $\mathrm{N}_{2}$ atmosphere (see Figure S7, Supporting Information) and helped to established the final chemical formula. Attempts to activate 1 (under different protocols) for measuring $\mathrm{N}_{2}$ isotherms proved unsuccessful, most likely related to its loss of structural stability when all molecule solvents were removed.

The photocatalytic activity of MOF 1 for the degradation of BG dye was then investigated. For this purpose, $25 \mathrm{mg}$ of 1 were suspended in $50 \mathrm{~mL}$ of a $10 \mathrm{ppm}$ aqueous solution of BG. Prior to irradiation, the mixture was kept in the dark for $30 \mathrm{~min}$ to verify that degradation only occurs under irradiation. After that period, the suspension started to be irradiated, under mild stirring at $250 \mathrm{~nm}$. At different times (5, 15, 30, 60, and $120 \mathrm{~min}$ ), $1 \mathrm{~mL}$ aliquots were taken, centrifuged, and diluted, and their UV-Vis absorption spectra were registered (Figure 6a). An identical experiment was performed, under the same conditions, in the absence of 1 (Figure S8). In order to have a better characterization of 1 , we performed UV-Vis diffuse reflectance spectroscopy, which revealed a strong adsorption band below $350 \mathrm{~nm}$ (Figure S9). 


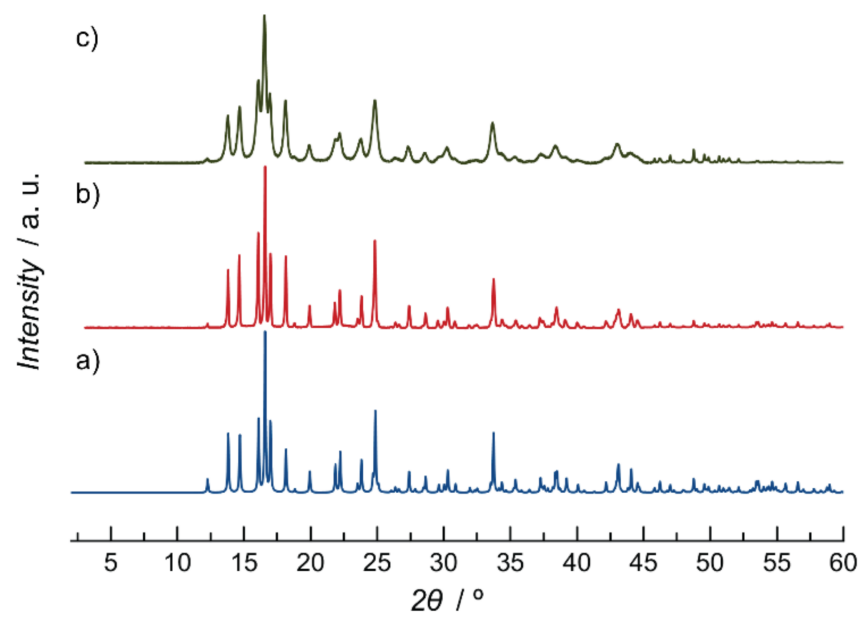

Figure 5. Calculated (a) and experimental (b) PXRD patterns of 1 in the $2 \theta$ range $2.0-60.0^{\circ}$ at R.T. (c) Experimental PXRD pattern of 1 after three consecutive cycles of photocatalytic degradation of BG.
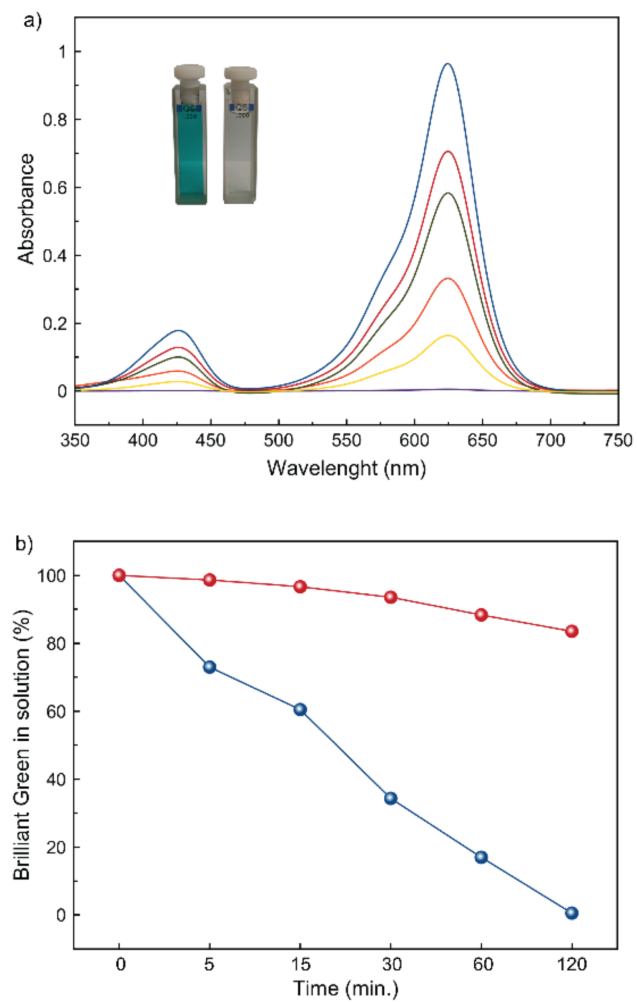

Figure 6. (a) Evolution with time of the UV-Vis absorption spectra of $10 \mathrm{ppm}$ solutions of brilliant green in water in the presence of $25 \mathrm{mg}$ of a polycrystalline sample of 1 . Blue: $t=0$; Red: $t=5 \mathrm{~min}$; Green: $t=15 \mathrm{~min}$;; Orange $=30 \mathrm{~min}$; Yellow: $t=60 \mathrm{~min}$; Purple: $t=120 \mathrm{~min}$. The inset shows the $\mathrm{BG}$ solutions at $\mathrm{t}=0 \mathrm{~min}$. (left) and $120 \mathrm{~min}$. (right) of exposure of the BG solution with MOF 1. (b) Kinetic profile of the degradation of brilliant green under irradiation at $250 \mathrm{~nm}$ in the presence of MOF 1 (blue) and with no photocatalyst (red).

Figure 6 shows the photodegradation efficiency of 1 towards BG. Such efficiency was evaluated by measuring the decrease in the characteristic absorption bands of BG dye, which appear at $420 \mathrm{~nm}$ and $625 \mathrm{~nm}$, respectively. Thus, under irradiation in the presence of 1 , it a gradual decrease of both peaks with time can be observed, until the vanish completely after 120 min (Figure 6a), which indicates that 100\% of BG dye is eliminated after that time (Figure 6b). In turn, the same experiment, in the absence of 1, (Figure S8 and Figure 6b), 
shows a very smooth decrease of the UV-Vis absorption bands, confirming the key role of 1 as photocatalyst. Tauc plot of the Kubelka-Munk function (Figure S10) allowed us to obtain an estimation of the optical band of $1(3.03 \mathrm{eV})$, which evidenced the suitability of it to perform the degradation of BG. Moreover, the reuse capability of 1 was stablished by both UV-Vis and PXRD experiments. On the one hand, two more UV-Vis vs. time experiments were carried out, using 1 as photocatalyst, with identical results (Figure S11), confirming that 1 can be employed in at least 3 cycles. On the other hand, PXRD patterns of 1 after three cycles are identical to those of the synthesized material suggesting that no degradation occurs during the photocatalytic process (Figure 5c).

The full degradation of the organic dye was also supported by thermogravimetric analysis coupled with mass spectrometry (TGA-MS) on $\mathrm{CO}_{2} @ 1$ (Figure S12). The weight loss in TGA led to two peaks in MS spectra with the mass to charge ratio $(\mathrm{m} / \mathrm{z})$ of 18 and 44 , which can be attributed to water and carbon dioxide. However, the amount of $\mathrm{CO}_{2}$ desorbed was lower than that obtained from X-ray crystallography. Most likely, this is related to some losses of $\mathrm{CO}_{2}$ during the handling of the measurement itself. The larger size of brilliant green dye compared to 1 pore size precluded the adsorption of the organic dye on MOF channels to perform the photocatalytic event. Thus, the photocatalytic activity of 1 most likely will arise from the crystal surface. With the aim of confirming the photodegradation's occurrance at the surface of 1, we measured the evolution of the BG concentration in solution when it is put in contact with 1 during 30 min in the dark. As can be observed in Figure S13, there is no appreciable difference in the BG concentration in solution, which supports our hypothesis. A leaching test ruled out the possibility of decomposition products of $\mathrm{Zn}$-based MOF being responsible for the photocatalytic degradation of brilliant green. This was also supported, in an indirect manner, by the maintenance of both the activity in the recyclability studies (Figure S11) and the high crystallinity of PXRD diffraction patterns after the photocatalytic process (Figure S5c).

A plausible mechanism for the degradation of BG dye is shown in Scheme S1. With the aid of UVC light, 1 generates electron and hole pairs. While the electrons jump to the conducting band, the holes remain in the valence band. The holes were scavenged by water molecules leading to energetically reactive hydroxyl radicals, and the photogenerated electrons react with $\mathrm{O}_{2}$ to produce the superoxide radical anions of oxygen. From them, based on literature precedents [50-53], the $\mathrm{OH} \bullet$ is believed to be the dominant oxidizing agent for the mineralization of BG dye into $\mathrm{CO}_{2}$ and $\mathrm{H}_{2} \mathrm{O} .{ }^{1} \mathrm{H}$ NMR of solutions after photocatalytic experiment do not show any peaks (apart from $\mathrm{H}_{2} \mathrm{O}$ ) that can be attributed to any known intermediate from a previously reported study. ${ }^{55}$ With the aim of exploring the formation of intermediate species, we performed liquid chromatography/tandem mass spectrometry (LC-MS/MS) on solutions after $30 \mathrm{~min}$. of UV irradiation, where we were able to identify four degradation molecules (Scheme S2) [54].

\section{Conclusions}

In summary, we have reported a novel, eco-friendly Zn-based MOF with the formula $\left\{\mathrm{Zn}_{2}[(S, S)\right.$-serimox $\left.]\left(\mathrm{H}_{2} \mathrm{O}\right)_{2}\right] \cdots \mathrm{H}_{2} \mathrm{O}(1)$ and its performance as a photocatalyst of BG aqueous solutions. This MOF with good water stability was able to efficiently photodegrade $10 \mathrm{ppm}$ aqueous solutions of BG in $120 \mathrm{~min}$. Indeed, UV-Vis spectroscopy measurements of irradiated solutions, with and without the presence of 1 , clearly revealed the photodegradation role of the framework. Single-crystal X-ray crystallography was applied not only to structurally characterize the pristine structure of 1 , but more interestingly, after the photocatalytic process. The resolution of the crystal structure of $\mathrm{CO}_{2} @ 1$ allowed us to confirm the total degradation of the dye and the presence of $\mathrm{CO}_{2}$ molecules (from the degradation process) retained within the irregular hydrophilic channels of 1 . Reusability tests of 1 , with up to 3 cycles of the photodegradation process, evidenced structural and performance robustness, which further confirms the viability of 1 as an efficient photocatalyst. Our current work is focused on extending this study to other Zn-based MOFs derived from natural amino acids. 
Supplementary Materials: The following are available online at, experimental preparation, analytical and spectroscopic characterization of 1, and additional Figures S1-S13, Table S1, Schemes S1 and S2.

Author Contributions: Conceptualization, D.A., E.P. and J.F.-S.; methodology, P.E., M.V.-C. and R.B.; formal analysis, D.A., E.P. and J.F.-S.; investigation, P.E., M.V.-C. and R.B.; writing-original draft preparation, P.E., M.V.-C. and R.B.; writing-review and editing, D.A., E.P. and J.F.-S.; supervision, D.A., E.P. and J.F.-S.; project administration, D.A., E.P. and J.F.-S.; funding acquisition, D.A., E.P. and J.F.-S.. All authors have read and agreed to the published version of the manuscript.

Funding: This research received no external funding.

Institutional Review Board Statement: Not applicable.

Informed Consent Statement: Not applicable.

Data Availability Statement: CCDC 2062289-2062290 contains the supplementary crystallographic data for this paper. These data can be obtained free of charge via www.ccdc.cam.ac.uk/data_request/ cif (accessed on 3 July 2021), or by emailing data_request@ccdc.cam.ac.uk, or by contacting The Cambridge Crystallographic Data Centre, 12 Union Road, Cambridge CB2 1EZ, UK; Fax: +44-1223336033.

Acknowledgments: This work was supported by the Ministero dell'Istruzione, dell'Università e della Ricerca (Italy) and the MINECO (Spain) (Projects PID2019-104778GB-I00 and Excellence Unit "Maria de Maeztu" CEX2019-000919-M). R. B. thanks the MIUR (Project PON R\&I FSE-FESR 2014-2020) for the predoctoral grant. D.A. acknowledges the financial support of the Fondazione CARIPLO/"Economia Circolare: ricerca per un futuro sostenibile" 2019, project code: 2019-2090, MOCA. E.P. acknowledges the financial support of the European Research Council under the European Union's Horizon 2020 research and innovation programme/ERC Grant Agreement No 814804, MOF-reactors. Thanks are also extended to the "2019 Post-doctoral Junior Leader-Retaining Fellowship, la Caixa Foundation (ID100010434 and fellowship code LCF/BQ/PR19/11700011" and "Subvenciones concedidas a la excelencia científica de juniors investigadores, SEJI/2020/034" (J. F.S.). We would like to thank Antonio Leyva-Pérez and Alejandro Vidal-Moya (Instituto de Tecnología Química, Universidad Politècnica de València-Consejo Superior de Investigaciones Científicas) for their help with solid-state ${ }^{13} \mathrm{C}$ NMR experiments.

Conflicts of Interest: The authors declare no conflict of interest.

Sample Availability: Samples of compounds 1 is available from the authors.

\section{References}

1. U.S. Environmental Protection Agency. 2012 ed. of the Drinking Water Standards and Health Advisories. 2012. Available online: https: / / rais.ornl.gov/documents/2012_drinking_water.pdf (accessed on 10 June 2021).

2. United Nations. Transforming Our World: The 2030 Agenda for Sustainable Development. 2015. Available online: https: / / sustainabledevelopment.un.org/post2015/transformingourworld (accessed on 10 June 2021).

3. Yagub, M.T.; Sen, T.K.; Afroze, S.; Ang, H.M. Dye and its removal from aqueous solution by adsorption: A review. Adv. Colloid. Interface Sci. 2014, 209, 172-184. [CrossRef]

4. Ahmad, A.; Mohd-Setapar, S.H.; Chuong, C.S.; Khatoon, A.; Wani, W.A.; Kumar, R.; Rafatullah, M. Recent advances in new generation dye removal technologies: Novel search for approaches to reprocess wastewater. RSC Adv. 2015, 5, 30801-30818. [CrossRef]

5. Yang, Z.; Wang, F.; Zhang, C.; Zeng, G.; Tan, X.; Yu, Z.; Zhong, Y.; Wang, H.; Cui, F. Utilization of LDH-based materials as potential adsorbents and photocatalysts for the decontamination of dyes wastewater: A review. RSC Adv. 2016, 6, 79415-79436. [CrossRef]

6. Gupta, N.K.; Ghaffari, Y.; Kim, S.; Bae, J.; Kim, K.S.; Saifuddin, M. Photocatalytic Degradation of Organic Pollutants over MFe ${ }_{2} \mathrm{O}_{4}$ (M = Co, Ni, Cu, Zn) Nanoparticles at Neutral pH. Sci. Rep. 2020, 10, 4942. [CrossRef] [PubMed]

7. Dias, E.M.; Petit, C. Towards the use of metal-organic frameworks for water reuse: A review of the recent advances in the field of organic pollutants removal and degradation and the next steps in the field. J. Mater. Chem. A 2015, 3, 22484-22506. [CrossRef]

8. Mon, M.; Bruno, R.; Ferrando-Soria, J.; Armentano, D.; Pardo, E. Metal-Organic Framework Technologies for Water Remediation: Towards a Sustainable Ecosystem. J. Mater. Chem. A 2018. [CrossRef]

9. Tiburcio, E.; Greco, R.; Mon, M.; Ballesteros-Soberanas, J.; Ferrando-Soria, J.; López-Haro, M.; Hernández-Garrido, J.C.; OliverMeseguer, J.; Marini, C.; Boronat, M.; et al. Soluble/MOF-Supported Palladium Single Atoms Catalyze the Ligand-, Additive-, and Solvent-Free Aerobic Oxidation of Benzyl Alcohols to Benzoic Acids. J. Am. Chem. Soc. 2021, 143, 2581-2592. [CrossRef] 
10. Wang, Q.; Gao, Q.; Al-Enizi, A.M.; Nafady, A.; Ma, S. Recent advances in MOF-based photocatalysis: Environmental remediation under visible light. Inorg. Chem. Front. 2020, 7, 300-339. [CrossRef]

11. Rojas, S.; Horcajada, P. Metal-Organic Frameworks for the Removal of Emerging Organic Contaminants in Water. Chem. Rev. 2020, 120, 8378-8415. [CrossRef]

12. Jiang, D.; Chen, M.; Wang, H.; Zeng, G.; Huang, D.; Cheng, M.; Liu, Y.; Xue, W.; Wang, Z. The application of different typological and structural MOFs-based materials for the dyes adsorption. Coord. Chem. Rev. 2019, 380, 471-483. [CrossRef]

13. Parmar, B.; Bisht, K.K.; Rajput, G.; Suresh, E. Recent advances in metal-organic frameworks as adsorbent materials for hazardous dye molecules. Dalt. Trans. 2021, 50, 3083-3108. [CrossRef]

14. Furukawa, H.; Cordova, K.E.; O’Keeffe, M.; Yaghi, O.M. The Chemistry and Applications of Metal-Organic Frameworks. Science 2013, 341, 974. [CrossRef]

15. Maurin, G.; Serre, C.; Cooper, A.; Férey, G. The new age of MOFs and of their porous-related solids. Chem. Soc. Rev. 2017, 46, 3104-3107. [CrossRef] [PubMed]

16. Kitagawa, S.; Matsuda, R. Chemistry of coordination space of porous coordination polymers. Coord. Chem. Rev. 2007, 251, 2490-2509. [CrossRef]

17. Férey, G. Hybrid porous solids: Past, present, future. Chem. Soc. Rev. 2008, 37, 191-214. [CrossRef] [PubMed]

18. Long, J.R.; Yaghi, O.M. The pervasive chemistry of metal-organic frameworks. Chem. Soc. Rev. 2009, 38, 1213-1214. [CrossRef]

19. Farha, O.K.; Hupp, J.T. Rational Design, Synthesis, Purification, and Activation of Metal-Organic Framework Materials. Acc. Chem. Res. 2010, 43, 1166-1175. [CrossRef]

20. Cui, Y.; Li, B.; He, H.; Zhou, W.; Chen, B.; Qian, G. Metal-Organic Frameworks as Platforms for Functional Materials. Acc. Chem. Res. 2016, 49, 483-493. [CrossRef] [PubMed]

21. Kirchon, A.; Feng, L.; Drake, H.F.; Joseph, E.A.; Zhou, H.-C. From fundamentals to applications: A toolbox for robust and multifunctional MOF materials. Chem. Soc. Rev. 2018, 47, 8611-8638. [CrossRef] [PubMed]

22. Jaramillo, D.E.; Reed, D.A.; Jiang, H.Z.H.; Oktawiec, J.; Mara, M.W.; Forse, A.C.; Lussier, D.J.; Murphy, R.A.; Cunningham, M.; Colombo, V.; et al. Selective nitrogen adsorption via backbonding in a metal-organic framework with exposed vanadium sites. Nat. Mater. 2020, 19, 517-521. [CrossRef]

23. Farha, O.K.; Eryazici, I.; Jeong, N.C.; Hauser, B.G.; Wilmer, C.E.; Sarjeant, A.A.; Snurr, R.Q.; Nguyen, S.T.; Yazaydın, A.Ö.; Hupp, J.T. Metal-Organic Framework Materials with Ultrahigh Surface Areas: Is the Sky the Limit? J. Am. Chem. Soc. 2012, 134, 15016-15021. [CrossRef] [PubMed]

24. Gonzalez, M.I.; Turkiewicz, A.B.; Darago, L.E.; Oktawiec, J.; Bustillo, K.; Grandjean, F.; Long, G.J.; Long, J.R. Confinement of atomically defined metal halide sheets in a metal-organic framework. Nature 2020, 577, 64-68. [CrossRef] [PubMed]

25. Mon, M.; Bruno, R.; Sanz-Navarro, S.; Negro, C.; Ferrando-Soria, J.; Bartella, L.; di Donna, L.; Prejanò, M.; Marino, T.; Leyva-Pérez, A.; et al. Hydrolase-like catalysis and structural resolution of natural products by a metal-organic framework. Nat. Commun. 2020, 11, 3080. [CrossRef] [PubMed]

26. Bloch, W.M.; Champness, N.R.; Doonan, C.J. X-ray Crystallography in Open-Framework Materials. Angew. Chemie Int. Ed. 2015, 54, 12860-12867. [CrossRef]

27. Rissanen, K. Crystallography of encapsulated molecules. Chem. Soc. Rev. 2017, 46, 2638-2648. [CrossRef]

28. Inokuma, Y.; Arai, T.; Fujita, M. Networked molecular cages as crystalline sponges for fullerenes and other guests. Nat. Chem. 2010, 2, 780-783. [CrossRef]

29. Young, R.J.; Huxley, M.T.; Pardo, E.; Champness, N.R.; Sumby, C.J.; Doonan, C.J. Isolating reactive metal-based species in Metal-Organic Frameworks - viable strategies and opportunities. Chem. Sci. 2020, 11, 4031-4050. [CrossRef] [PubMed]

30. Bloch, W.M.; Burgun, A.; Coghlan, C.J.; Lee, R.; Coote, M.L.; Doonan, C.J.; Sumby, C.J. Capturing snapshots of post-synthetic metallation chemistry in metal-organic frameworks. Nat. Chem. 2014, 6, 906-912. [CrossRef] [PubMed]

31. Viciano-Chumillas, M.; Mon, M.; Ferrando-Soria, J.; Corma, A.; Leyva-Pérez, A.; Armentano, D.; Pardo, E. Metal-Organic Frameworks as Chemical Nanoreactors: Synthesis and Stabilization of Catalytically Active Metal Species in Confined Spaces. Acc. Chem. Res. 2020, 53, 520-531. [CrossRef]

32. Burgun, A.; Coghlan, C.J.; Huang, D.M.; Chen, W.; Horike, S.; Kitagawa, S.; Alvino, J.F.; Metha, G.F.; Sumby, C.J.; Doonan, C.J. Mapping-Out Catalytic Processes in a Metal-Organic Framework with Single-Crystal X-ray Crystallography. Angew. Chemie Int. Ed. 2017, 56, 8412-8416. [CrossRef]

33. Kobielska, P.A.; Howarth, A.J.; Farha, O.K.; Nayak, S. Metal-organic frameworks for heavy metal removal from water. Coord. Chem. Rev. 2018, 358, 92-107. [CrossRef]

34. Gao, Q.; Xu, J.; Bu, X.-H. Recent advances about metal-organic frameworks in the removal of pollutants from wastewater. Coord. Chem. Rev. 2019, 378, 17-31. [CrossRef]

35. Mon, M.; Bruno, R.; Tiburcio, E.; Viciano-Chumillas, M.; Kalinke, L.H.G.; Ferrando-Soria, J.; Armentano, D.; Pardo, E. Multivariate Metal-Organic Frameworks for the Simultaneous Capture of Organic and Inorganic Contaminants from Water. J. Am. Chem. Soc. 2019, 141, 13601-13609. [CrossRef] [PubMed]

36. Sharma, V.K.; Feng, M. Water depollution using metal-organic frameworks-catalyzed advanced oxidation processes: A review. J. Hazard. Mater. 2017. [CrossRef]

37. Wu, Z.; Yuan, X.; Zhang, J.; Wang, H.; Jiang, L.; Zeng, G. Photocatalytic Decontamination of Wastewater Containing Organic Dyes by Metal-Organic Frameworks and their Derivatives. ChemCatChem 2017, 9, 41-64. [CrossRef] 
38. Zeng, L.; Guo, X.; He, C.; Duan, C. Metal-Organic Frameworks: Versatile Materials for Heterogeneous Photocatalysis. ACS Catal. 2016, 6, 7935-7947. [CrossRef]

39. Wang, C.-C.; Li, J.-R.; Lv, X.-L.; Zhang, Y.-Q.; Guo, G. Photocatalytic organic pollutants degradation in metal-organic frameworks. Energy Environ. Sci. 2014, 7, 2831-2867. [CrossRef]

40. Zhang, T.; Lin, W. Metal-organic frameworks for artificial photosynthesis and photocatalysis. Chem. Soc. Rev. 2014, 43, 5982-5993. [CrossRef] [PubMed]

41. Chimupala, Y.; Phromma, C.; Yimklan, S.; Semakul, N.; Ruankham, P. Dye wastewater treatment enabled by piezo-enhanced photocatalysis of single-component ZnO nanoparticles. RSC Adv. 2020, 10, 28567-28575. [CrossRef]

42. Tian, C.; Zhang, Q.; Wu, A.; Jiang, M.; Liang, Z.; Jiang, B.; Fu, H. Cost-effective large-scale synthesis of ZnO photocatalyst with excellent performance for dye photodegradation. Chem. Commun. 2012, 48, 2858. [CrossRef]

43. Dong, J.-P.; Shi, Z.-Z.; Li, B.; Wang, L.-Y. Synthesis of a novel 2D zinc(II) metal-organic framework for photocatalytic degradation of organic dyes in water. Dalt. Trans. 2019, 48, 17626-17632. [CrossRef] [PubMed]

44. Zhang, C.; Ma, D.; Zhang, X.; Ma, J.; Liu, L.; Xu, X. Preparation, structure and photocatalysis of metal-organic frameworks derived from aromatic carboxylate and imidazole-based ligands. J. Coord. Chem. 2016, 69, 985-995. [CrossRef]

45. Jing, H.-P.; Wang, C.-C.; Zhang, Y.-W.; Wang, P.; Li, R. Photocatalytic degradation of methylene blue in ZIF-8. RSC Adv. 2014, 4, 54454-54462. [CrossRef]

46. Mon, M.; Bruno, R.; Tiburcio, E.; Grau-Atienza, A.; Sepúlveda-Escribano, A.; Ramos-Fernandez, E.V.; Fuoco, A.; Esposito, E.; Monteleone, M.; Jansen, J.C.; et al. Efficient Gas Separation and Transport Mechanism in Rare Hemilabile Metal-Organic Framework. Chem. Mater. 2019, 31, 5856-5866. [CrossRef]

47. Rufino-Felipe, E.; Caballero-Jiménez, J.; Guerrero-Ramírez, L.-G.; Flores-Álamo, M.; Muñoz-Hernández, M.-Á. Novel hexanuclear and octanuclear zinc alkyl cages derived from a bis-oxamidate ligand. Inorg. Chem. Commun. 2016, 63, 107-110. [CrossRef]

48. Desmarais, W.T.; Bienvenue, D.L.; Bzymek, K.P.; Holz, R.C.; Petsko, G.A.; Ringe, D. The $1.20 \AA$ A Resolution Crystal Structure of the Aminopeptidase from Aeromonas proteolytica Complexed with Tris. Structure 2002, 10, 1063-1072. [CrossRef]

49. Ataie, N.J.; Hoang, Q.Q.; Zahniser, M.P.D.; Tu, Y.; Milne, A.; Petsko, G.A.; Ringe, D. Zinc Coordination Geometry and Ligand Binding Affinity: The Structural and Kinetic Analysis of the Second-Shell Serine 228 Residue and the Methionine 180 Residue of the Aminopeptidase from Vibrio proteolyticus. Biochemistry 2008, 47, 7673-7683. [CrossRef] [PubMed]

50. Sood, S.; Umar, A.; Mehta, S.K.; Sinha, A.S.K.; Kansal, S.K. Efficient photocatalytic degradation of brilliant green using Sr-doped $\mathrm{TiO}_{2}$ nanoparticles. Ceram. Int. 2015, 41, 3533-3540. [CrossRef]

51. Shanmugam, N.; Sathya, T.; Viruthagiri, G.; Kalyanasundaram, C.; Gobi, R.; Ragupathy, S. Photocatalytic degradation of brilliant green using undoped and $\mathrm{Zn}$ doped $\mathrm{SnO}_{2}$ nanoparticles under sunlight irradiation. Appl. Surf. Sci. 2016, 360, 283-290. [CrossRef]

52. Migliorini, F.L.; Steter, J.R.; Rocha, R.S.; Lanza, M.R.V.; Baldan, M.R.; Ferreira, N.G. Efficiency study and mechanistic aspects in the Brilliant Green dye degradation using BDD/Ti electrodes. Diam. Relat. Mater. 2016, 65, 5-12. [CrossRef]

53. Kaur, S.; Sharma, S.; Umar, A.; Singh, S.; Mehta, S.K.; Kansal, S.K. Solar light driven enhanced photocatalytic degradation of brilliant green dye based on ZnS quantum dots. Superlattices Microstruct. 2017, 103, 365-375. [CrossRef]

54. Rehman, F.; Sayed, M.; Khan, J.A.; Shah, N.S.; Khan, H.M.; Dionysiou, D.D. Oxidative removal of brilliant green by UV/ ${ }_{2} \mathrm{O}_{8}{ }^{2-}$, $\mathrm{UV} / \mathrm{HSO}_{5}{ }^{-}$and $\mathrm{UV} / \mathrm{H}_{2} \mathrm{O}_{2}$ processes in aqueous media: A comparative study. J. Hazard. Mater. 2018, 357, 506-514. [CrossRef] [PubMed] 